\title{
Issue and Challenges of Adopting Contraception Methods by Men and Women in Rural Uttar Pradesh
}

\author{
Vimlesh Kumari, Chitra Khetwal
}

\begin{abstract}
India stand second in the world in terms of population containing $17.50 \%$ of the world's population. $70 \%$ population of India lives in village in which $64 \%$ population's occupational structure is primary. Due to this, so many problems are creating and increasing daily like unemployment, health related problem, starvation and poverty etc.

To solve or rid from these problems, Government of India committed itself or started to bring about the sustainable development in rural India through various programs. The aim of these programs has to cover all the facts of rural life for improving the life of three- fourth of Indian who lives in the villages. But family planning and adopting contraception methods are so easier than others, and population or other population related problems can be control easily. In this paper we describe many issue and challenges spread in the society. There are main social, political and economic etc. Issues and challenges to adopting the contraception method among the people.
\end{abstract}

Keywords: Contraception method; rural development; parameters of healthcare: STDs.

\section{INTRODUCTION}

India is an agriculture based country. A large no. of population of India is lived in rural area. As per the census conducted in year 2011 the population of India was over 121 crore. Where, about 83.3 crores are the habitants of villages. Around $30 \%$ of 108 million rural household are depend on agriculture labor, $58 \%$ are marginal farmers who are the owner of less than 1 hectare land, and $18 \%$ are the owner of less than 2 hectare land.

This part of the total population is illiterate; suffer from inflation, poverty, unemployment and, poor nutrition and health problems and diseases.

They are so far from the development. They are unknown from the new and modern technologies, new infrastructure and so any other modern facility and changes. They don't know about the new Government Plans, programs and schemes inhabitants.

Revised Manuscript Received on February 12, 2020.

* Correspondence Author

Vimlesh Kumari*, Noida International University, Greater Noida, India. Email: vimleshkumari22292@gmail.com

Chitra Khetwal, Noida International University, Greater Noida, India. Email: Chitravichitra57@gmail.com

(C) The Authors. Published by Blue Eyes Intelligence Engineering and Sciences Publication (BEIESP). This is an open access article under the CC BY-NC-ND license (http://creativecommons.org/licenses/by-nc-nd/4.0/)
The government of NGO's implements a number of rural development program in order to address these specific problems to improve the quality of life.

The life of people living in rural area. The government of India has launched many schemes under the ambit of planning committee on of India. Among these schemes such as Mahatma Gandhi National Rural Employment Guarantee Act (MGNREGA), Rastriya Sama Vikas Yojana (RSVY), Indira Awas Yojana (IAY), Sampoorna Grameen Rozgar Yojana (SGRY), Integrated Trivial Development Project (ITDP), Pradhan Mantri Gram Sadak Yojana (PMGSY), Integrated Child Development Services (ICDS), Development of Women and children in Rural Areas (DWCRA) are some of the major schemes that have brought about changes in the life of rural people of their schemes aim to minimize the gap between the rural population and the urban by sustainable development.

The large number of author have put their efforts in to the study of MGNREGA to underline in detail its related problem. One of the author Dreze[9] (2007) views and underline the problems of prevailing corruption in the rural development program in the state of Orissa and finds that it is also visible underneath in MGNREGA as well N.RHIA has continued this scheme. Another author Mathur[10](2007) says that there is the continuous flow of authoetative information and a regular system. which is opposed to the random report and studies depending on the individual and the groups.

Ambasta et al.[11] (2008) get different significant commendations. At the Block Level MGNREGA has include dispersion or expansion of full-time professionals. Intensive effort at building up a massive cadre of fully Mehrotra[12] (2008) finds that more than $4 \%$ program cost spent under administrative costs and professional support has still very low and ignore the reality that a program like MGNREGA need serious professional supported and expertise.

Khera[13] (2008) finds that the implementation of MGNREGA in Orissa's Pati Block has been above the expectation of the residents claims and rights. This has been brought out by the higher level of engagements related to the program associated with planning, monitoring and implementation. Mathur[14] (2009) Finds that some people reportedly had not even been paid properly for their work they did for MGNREGA as per the social audit undertaken in Andhra Pradesh.

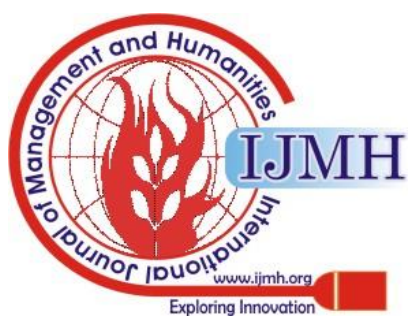




\section{RELATED WORK}

Many author have put their efforts into the study of the government programs and different types of approaches have been proposed for rural. In the present review paper,

we reviewed the socio-economic and cultural conditions respondents play an important role in a research / study, because it is necessary and essential to understand the major variables used under study. Muthaiya ${ }^{1}$ (2003) has stated that the variables play an important role to draw logical conclusions regarding the study problem. The researcher has studied the socio-demographic profile of men and women respondents selected for study as target subjects/respondents. Therefore, first of all it is necessary to understand the meaning and the concept of the word 'family'. Sociologist MacIver and Page ${ }^{2}$ have stated that 'Family is the first \& most important institution of the society around which the whole society revolves'. No society or any part of the society can ignore the paramount importance \& significance of the social institution. That's why, it is said that the family for children is a cradle; for youth is garden and for old-age it is the hospital or shelter.

According to Anderson \& $\operatorname{Parker}^{3}(1960$ : 15); the family has two forms as: (i) family of orientation, and (ii) Family of procreation. Harskovits M.J.[4] though it is also said that 'Culture is the man-made part of the environment ${ }^{4}$. It is clear that all human products are the part of human culture, and all these products effect the society. Hans Raj [5] to study socio-cultural and socio-demographic and socio-economic aspects of any community or group, it is essential to study the various aspects which are known as continuant classified the related variables into two major parts- (1) Dependent variables (2) Independent variables for study

As we know that the family has two norms: (a) Family of orientation (b) Family of procreation; sociologists like Kingsley Devis ${ }^{6}$ (1977;80), Burges E.W. ${ }^{7}$ (The Family, 1953:8) and MacIver \& Page $^{8}$ (Society, 1959:243) have defined family well. Bothmen and women have been selected for study "Evaluation of Pradhan Mantri Jan-Dhan Yojana (PMJDY) in Rural Development (A Sociologist Study).

Jessica L. Morris , H. Rushwan[16] describe FIGO have an important role to play in the advancement of ASRH services so that healthcare workers move from being part of the problem to part of the solution and to enabling obstetricians and gynecologists to effect change in their countries and support the ASRH agenda on a universal scale.

Natasha Kumar, and Joanna D. Brown,[17]. Explore the guidelines published by the American Academy of Pediatrics in United States create a new feelings of most of the people that long-acting reversible contraceptives as first-line contraception for adolescents and Systemic policy interference such as the Affordable Care Act's mandate that contraceptive amount or distribution be a part of necessary health benefits for all insurance providers.

Tom Lutalo1, Ron Gray2, et al [18] Longitudinal data was used to estimate rates of unfulfilled need for contraception and authors asked whether they intended to use any method of contraception until they desired a child. Modified Poisson multivariate regression was used to estimate unadjusted and adjusted prevalence ratios (PR) and 95\% CI of unfulfilled need for contraception.

Moazzam Ali1, Syed Khurram Azmat2, [19]using the David and Lucile Packard Foundation USA and Pakistan funded from 2012 to 2015,these two voucher intervention programs among married women of reproductive age (MWRA) who received contraceptive and FP services through vouchers and will help to provide information to policy makers to develop and to sustain the positive behavior change in the population.

Joseph M. Zulu1 and Joseph Ali et al. [20] suggested strategies for addressing the ethical challenge. An increase in post abortion care (PAC) research with adolescents particularly in low- and middle-income countries, that researchers face when conducting a scoping review of published literature PAC .

Yolandie Kriel, Cecilia Milford et al. [21] explore the perception and attitude towards of male family planning and contraceptive (FP/C) uptake, whether positively or negatively and It use is important in intercepting inadvertent pregnancies and improving FP policy and services delivery programs in South Africa.

A.Francis, S. Jasani et al. [22]address the awareness of healthcare disparities experienced by transgender men in midlife, including their contraceptive needs and pregnancy desires. Clinicians should be on the forefront of promoting strategies that make collaborative relationship with the transgender man, including as he transitions through to the menopause and his sexual and reproductive healthcare needs paper in the given email address of the journal. There are two email address. It is compulsory to send paper in both email address.

\section{NEED FOR CONTRAEPTION}

On January 1 2020, total 7, 84000 children were born all over the world and remarkable out of 7,84000 children 69000 were born alone in India which is the highest among all the countries world over. If the population explodes at the same speed we will beat china b 2027 in population growth which is not an achievement in any way.

The developed nation are fully dependent on their rural development. There is a need to change their lifestyle, livelihood and health problems etc. there are some suggestions for adopting contraceptives.

1) Contraceptives also help to avoid undesirable pregnancies and abortion thus are very effective in birth control and it can control the morbidity and maternal mortality.

2) With the help of suitable contraceptive method maternal death can be controlled and prevented easily or can also be helpful in saving life of thousands of mother who die every year during child labor.

3) Correct contraceptive methods are helpful to prevent and protect from sexual diseases like HIV /AIDS etc.

4) By adopting suitable contraceptives methods, the health level of mother and child can be improved which is necessary for the all-round development of child in society.

5) Use of contraceptives can be helpful in addressing the problem of child labour. When the parents fail to earn the send the children to work specially in underprivileged families where the parents have sizable number of children and cannot afford even their food and clothes. 


\section{ISSUES AND CHALLENGES}

There are many issues which are needed to found for proper exact data. In the giving lines, some issues and challenges are explained which are related to in this domain.

Issue:

The issues related to the rural development can be categories as under:

- Problem in society, religious and culture:

Intentionally, some culture bounded the use of contraceptive medicines because they think that these are unsuitable politically and ethically. There are so different opinions of different religion about the thinking of family planning. There are different pedantic vies of different religion about conceiving:

In some religion, they appreciate conceiving and in some religion, they refrain it, just like as, according to Islam- the children are god gift do marry and start the family.

Roman Catholic Church, officially appreciate only primary family planning. Bodda's views-obstacles are not accepted after conceiving.

\section{- Higher education:}

It should be a subject in higher education by which the students are informed and has a perfect knowledge and they can take the right or suitable precautions and its helpful for control the increasingly population.

Central government should be active to implement the contraception for the better future of the country. In case, government fails to do so, resulting will be world largest population. This will be a major obstacle for the progress of the country. The problem of employment, begging etc., will gradually increase.

- Users and providers bias:

The researchers analyzed that the married persons profile generally and checked their used method and their opinions situation and want to know they used method before and what was the result. The difference is this, providers never like to know or analyze the unmarried's profile. But they want to observe the unmarried's and married profile and they also exited to know which method was used by them generally.

- Economic view:

Due to poverty, the persons who are struggle in daily life cannot use these types of methods. This is the big issue for those whose source of income is low. These are out of range for them. They have not new or update gadgets, and not have any knowledge about these contraceptive. They are unfamiliar .They are so busy in their daily life or need such as food, clothes and residence.

\section{- Connectivity problem:}

In India, there are so many problems in broadcasting channel or sending information due to poor networking especially in rural or backwards areas. The peoples who live in backward or rural area, they don't know exact information about suitable methods. Internet is very fast and suitable medium for advertising any information or data to the peoples. The Government must improve their information and broadcasting. Example: BSNL is the worst government network in INDIA. Ministry of INFORMATION \& BROADCASTING must improve its condition and internet should be active in all areas. Though internet any suitable information may be provided to maximum population in minimum time.
- Advertisement:

The people either illiterate nor have knowledge about contraception, information should be publicized through any medium e.g. the banners, hoardings, TV advertisement etc. The September of 26, is celebrated as world contraceptive day. There are so many challenges for advertisement in the society.

\section{- Collection of reviews:}

Problem in collecting reviews: In non-developing areas, so many problems have to face by both the trainees and user like that communication skill, social or religious factors etc. In naxalism area, they never want that any other or unknown person entered in their area or advertise contraceptive method product for their development and can be helpful for their in habitants to aware against the naxalism. For this expert or trained staff must be attended or create any midway and it should not be danger for them or naxalism.

\section{- Hire a local expert:}

There are so many contraceptive methods in market. Most of contraception method are useful and not have side effects. But some of contraceptives are not useful but have some side effect. It can be harmful for them. People have no exact information about these methods. Neither they are suggested by any expert nor do they collect the reviews. For this solution, researcher should be showing their method's reviews and star rating and easily should be visible for the users. These methods will help them and users can save their life from disease and in futons.

\section{- Fake information:}

But some researchers show the fake information or views on internet for their benefit. They want their benefit and most of users use their contraceptives. They increase their reviews through their known person or other wrong way.

We must provide a way by which fake reviews or information can be remove or deleted. It will be helpful to collect the exact review for the users.

\section{Challenges:}

There are many challenges pertaining to the rural development which can be enlisted as below:

- Unwanted and unsafe pregnancies:

Unwanted pregnancy is the most troubling public health problem. It is undesired for one or both of the partners. According to WHO report in 2008 was 21-22 million globally and 22 unsafe abortion per 1000 women agreed 15 to 45 years. Due to unintended pregnancy, mothers are negative consequence. These types of mother highly exposed to suicide, depression, poor, physical and psychological violence, risk of miscarriage and having low birth weight infants and delayed onset of prenatal care.

\section{- Sexually transmitted disease:}

Some people use the method without have any information about their partner's disease. These harmful viruses transferred from one body to other body. They don't use any barrier protection during physical relation. Like HIV/AIDS is a lethal decease spread due to unknown relationship.

\section{- Barrier to uptake:}

There are so many female patients who never use any contraception method. Either they are not satisfy with the features of method or may be service provider's problem. 
They have no information or knowledge, what is the need. Many specific protections are also count those that are related to method that's why they use non-medical delivery of some methods increase access to contraception. Some new barriers for ladies begin from either contraceptive need these are depends on their life's stage and their desire of child.

\section{- Illiteracy}

In comparison of urban area, the rate of illiteracy is far above in rural area which causes poor awareness. Illiteracy becomes another challenge in creating awareness among the rural people as they cannot read even the simple suggestion given by family planning officials or understand the slogans and messages written on walls under the government campaign for birth control in rural areas.

\section{- Male child priority:}

To want a male child is the mentality of our backward society. Common wisdom is that the preference for sons is motivate by economic, religious, social and emotional desires and norms that favor males and females less desirable: parents expect sons but not daughter- to provide financial and emotional care , especially in their old age ; sons add to family wealth and property while daughters drain it through dowries; sons continue the family lineage while daughters are married awe to another household; sons perform important religious roles and sons defend and exercise the family's power while daughters have to be defended and protected, creating perceived burden on the household.

\section{- Limited choice of method:}

Maximum female want a family planning but they have no knowledge of contraceptive method or lack of knowledge according to age, cost, new update method and other features. $51 \%$ become pregnant unintended. At least 10\% have knowledge of contraceptive method. Other brand's methods due to high coast lost their market value.

The researcher should improve the quality of methods and provide the best methods to the women. Women should be aware and they have to select a suitable method which is helpful for them.

\section{- Gender based barrier}

In some areas about the community based female health and their family planning workers are responsible for gender based service for women. Although the training of such type of female worker is not easy to operate the female health worker with in the same gender system is neglected and to appointed them first is the priority. Some problems identified include: Abusive hierarchical management, Disrespect from male colleagues and Lack of sensitivity to women's gender based constraints. To increase the understanding of the experience of female staff working at community level is used in present and updated study

- Mostly contraceptives method are used by female:

In pateriachichal societies women are always at the receiving end. It is the male who dominates the family hence female is generally forced to use contraceptives in case the couple wants birth control. The other likely reasons relate to consummate the relationship for pleasure in backward males its general misconception that it's the responsibilities of the female to adopt the contraceptive to avoid unwanted pregnancy and at the same time taking care of the needs and pleasure of male.

\section{CONCLUSIONS}

On the basis of above investigation and we summarize that the rural development index has been suffering from the multi- dimensional problems. On one hand there is severe awareness among the rural people health and hygiene, mother and child care, using of contraceptives, lack of education and other related issue on the other hand lethargic implementation of government scheme. Not only this but also social, cultural and political issue also add to the challenges in the proper development of rural area.

The governments needs to, come out with more effective policies and proper implementation of existing policies there is also the need to create awareness among the rural people about mother and child care and also the society in general needs to co-operate and more receptive towards the government policies. The following things should be taken care for proper discharge of the government facilities to the people of rural areas in India.

1. People, especially girls should be given proper education about contraceptives at school level itself along with regular education. They should be told about the uses of contraceptives during their adolescent age. The schools and colleges are the right places from where women can be well informed about use of contraceptives.

2. There is the need of more sophisticated and safe contraceptives. So the government and other stakeholders should pay proper attention on research and invention of more safe, easier, and less costly contraceptive products so that the sexually transmitted diseases (STD) might be controlled. The contraceptive products should be easily be available to the poor people too.

3. Attention should also be given to the better connectivity, better medium of communication to the rural areas where birth rate is much higher. So that the access to these areas might be easy and to ensure the access of the related information about contraceptive methods and other related materials.

4. There is much scope to do at social, cultural and religious grounds to impart knowledge among the rural people to enhance the use of contraceptives to control the birth rate, population, and provide better health to mother and child. The political leaders should assist beyond their party line and irrespective of religion or culture in framing proper policies related to birth control, unwanted pregnancies and so on. Most of the efforts pertaining to population control go futile as politicians seem reluctant to address this problem as they fear of losing their vote bank. So the need of the hour is that government should frame strict but acceptable policies.

5. Apart from this people should also be provided with correct information and advantages of use of contraceptives at right time.

So that the family planning be ensured. Which ultimately ensure the better economic and health conditions of the families in the rural areas.

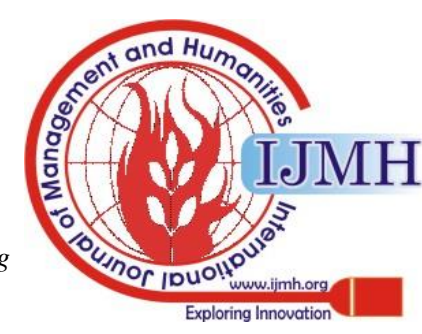




\section{REFERENCES}

1. MuthaiyaR.K,"Why the study of the profile of the respondents is essential in social problems," In the proceeding of Internationa Seminar, Organized by Tata Institute of Social work, Bombay, Feb 2003

2. MacIver R.M. \& Page C.H. ; Society: Mc-millian \& Co., London, 1959, p. 243.

3. Anderson\& Parker ; Society : It's Organisation and Operations, 1960, p.150.

4. Harskovits M.J. ; The Men and His works, Alfred AknoffPublishers (Pvt, Ltd.), New York, 1956, p.17

5. Hans Raj ; The Fundamentals of Demography (with special reference to India), Surjeet Publications, Delhi, 1978, p. 185.

6. Kingsley Devis ; Human Society; Quoted from: A New Dictionary by Mitchel G.D., Routledge and Kegan Paul Publishers, (Pvt. Ltd.) London (II Edition), 1977, p.80.

7. Burgess E.W. \& Lock E.B. ; The Family (1953), Quoted from the above Dictionary, 1977, p.80.

8. Mac Iver R.M. \& C.H. ; Society : Mc-Millian\& Co. London, 1959 Page 243. Quoted from Gupta K.L. \& Sharma R.P. Surjeet Publications, Delhi, 2010, p. 107.

9. Dreze J. (2007).MGNREGA : Dismantling the contractor raj. The Hindu, 20th November,2007.

10. Mathur L. (2007). "Employment Guarantee: Progress so far." Economic and political weekly, December 2007.

11. Ambasta, P., Shankar, P.S.V., \& Shah, M. (2008). Two years of MGNREGA: The road ahead. Economic and political Weekly , February 2008

12. Mehrotra, S. (2008). NREG two years on: Where do we go from here? Economic and Political weekly, August 2008.

13. Khera, R. "Empowerment Guarantee Act. Economic and Political Weekly," August 2008.

14. Mathur L. (2009)." Silent but Successful initiative." , The Hindu, 1st March,2009.

15. Dey. S., \&Bedi, A.(2010). The national Rural Employment Guarantee Scheme in Birbhum. Economic and Political Weekly, XLV(41), 19-25.

16. J. L. Morris, H.Rushwan "Adolescent sexual and reproductive health: The global challenges", In the International Journal of Gynaecology and Obstetrics,2015.

17. N. Kumar,Joanna D. Brown and et al., "Access Barriers to Long-Acting Reversible Contraceptives for Adolescents,"In the proceeding of the Journal of Adolescent Health, Elsevier, 2016.

18. T. Lutalo1, R. Gray2 and et al.,"Unfulfilled need for contraception among, women with unmet need but with theintention to use contraception in Rakai,Uganda: a longitudinal study," In the proceeding of BMC Women's Health, 2018.

19. M. Ali, S. K. Azmat,and et al. "Assessment of modern contraceptivescontinuation, switching anddiscontinuation among clients in Pakistan:study protocol of 24-months post family planning voucher intervention," In proceeding ofthe, BMC Health Services Research, 2018.

20. J. M. Zulu, J.Ali and et al.'Ethics challenges and guidance related toresearch involving adolescent post-abortioncare: a scoping review," In proceeding of the Reproductive Health, 2018.

21. Y. Kriel, C.Milford and et al."partner influence on family planningand contraceptive use: perspectives fromcommunity members and healthcareproviders", in KwaZulu-Natal, South Africa, In proceeding of the Reproductive Health,2019.

22. A. Francis, S. Jasani and Fransiset al."Contraceptive challenges and the transgender individual", at Women's Midlife Health,2018.

23. Z. B. Mengesha and et al."Challenges in the Provision of Sexual and Reproductive HealthCare to Refugee and Migrant Women: A $Q$ Methodological Study of Health Professional Perspectives," In proceedingof theJournal of Immigrant and Minority Health, June 2017.

\section{AUTHORS PROFILE}

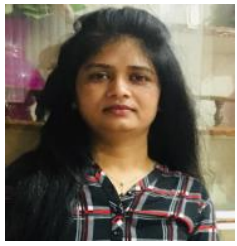

Ms. Vimlesh Kumari, presently pursuing her Ph.D from Noida International University. She did her Master in Sociology. Her area of research is rural society in India. She had attended many conferences on her area.

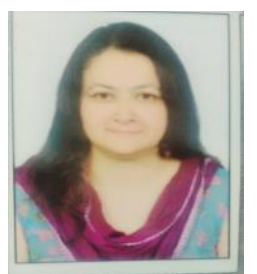

Dr. Chitra Khetwal, is working as an Associate Professor at Noida International University, Greater Noida. She had invited as a speaker in the Women Economic Forum 2019 and World Education Summit. She had worked in several theatre shows as well\& have written a book on Juvenile Dlinquency Attended Great India Debate with Kabir Bedi with such prominent speakers like Mani Shankar Aiyyar and Manish Tiwari. Attended 14th Higher Education Summit at FICCI with IIMs IITs \& Microsoft head on Panel.Attended Josh Talk along with UN women presents Hear me too, a campaign that explores the extent of violence against women and girls in India at Indian Habitat Centre. 